\title{
Portfólio: uma alternativa para o gerenciamento das situações de ensino e aprendizagem
}

\author{
ZILDA ROSSI ARAUJO \\ Bolsista do Núcleo de Estudos e Pesquisas em Avaliação Educacional. Aluna do \\ Programa de Mestrado em Educação da Universidade Estadual de Londrina - UEL \\ zilda.r@uol.com.br \\ GEORFRAVIA MONTOZA ALVARENGA \\ Coordenadora do Núcleo de Estudos e Pesquisas em Avaliação Educacional. \\ Professora do Departamento de Educação da \\ Universidade Estadual de Londrina - UEL \\ geomontoza@sercomtel.com.br
}

\begin{abstract}
Resumo
Este artigo é resultado de estudos e pesquisas realizados em um curso superior de formação de professores de uma instituição pública do Paraná. Buscou-se conhecer e compreender a utilização do portfólio como ferramenta para monitoramento do processo de ensino e aprendizagem. Para isso, fez-se o acompanhamento sistemático da aplicação da ferramenta de avaliação. O estudo configurou-se numa perspectiva qualitativa e foi desenvolvido com base nos dados coletados dos portfólios dos alunos que, após analisados, permitiram compreender o impacto das atividades propostas e a eficácia das práticas avaliativas inovadoras.
\end{abstract}

Palavras-chave: portfólio, ensino, aprendizagem, avaliação qualitativa, cotidiano escolar.

\section{Resumen}

Este artículo es resultado de estudios e investigaciones realizados en un curso superior de formación de profesores de una institución pública de Paraná. Se procuró conocer y comprender la utilización del porfolio como herramienta para monitorear el proceso de enseñanza y aprendizaje. Para eso, se hizo el acompañamiento sistemático de la aplicación de la herramienta de evaluación. El estudio se configuró en una perspectiva cualitativa y se desenvolvió basado en los datos recogidos en los porfolios de los alumnos que, después de analizados, permitieron comprender el impacto de las actividades propuestas y la eficacia de las prácticas de evaluación innovadoras.

Palabras-clave: porfolio, enseñanza, aprendizaje, evaluación cualitativa, cotidiano escolar. 


\begin{abstract}
This article reports on studies and research conducted at a Teacher Education college course at a public institution in the state of Paraná. We aimed at becoming acquainted with and understanding the use of portfolios as a tool to monitor the teaching and learning process through a systematic follow-up of the assessment tool's application. The study was carried out from a qualitative perspective and was based on the data collected from the students portfolios. The analysis of the data allowed us to understand the impact of the proposed activities and the effectiveness of innovative evaluation practices.

Key words: portfolio, teaching, learning, qualitative evaluation, school routine.
\end{abstract}




\section{INTRODUÇÃO}

Este trabalho fez parte de um projeto maior que investigou as práticas avaliativas emergentes no cotidiano escolar, cujo objetivo foi conhecer e compreender as questões sobre a avaliação educacional. A intenção foi elaborar um diagnóstico descritivo de uma prática emergente de avaliação que utilizou o portfólio como ferramenta de acompanhamento do processo de ensino e aprendizagem em um curso superior de formação de professores de uma instituição pública do Paraná, nos anos de 1999 a 2003.

Estudar o portfólio como uma prática avaliativa emergente no cotidiano escolar, verificando se o mesmo favorece a reflexão crítica dos envolvidos no processo, foi o que norteou a pesquisa. Assim, este trabalho circunscreve-se à análise do uso do portfólio como ferramenta de avaliação formativa, inserida no processo de ensino e aprendizagem dos alunos.

Este estudo teve como objetivos:

1. Caracterizar o portfólio como prática emergente para o processo de avaliação formativa e as possibilidades de sua utilização no Ensino Superior.

2. Analisar as técnicas e os instrumentos utilizados para avaliação durante o processo de ensino e aprendizagem, tendo o portfólio como ferramenta de acompanhamento.

3. Analisar a percepção dos alunos sobre seu desempenho, a partir da análise das reflexões que compõem os portfólios.

\section{ARQUITETURA DA PESQUISA}

O trabalho se configura numa perspectiva qualitativa, na qual os dados coletados são predominantemente descritivos; as situações, os fatos, os depoimentos, os documentos ajudam a descrever o contexto (Ludke, André, 1986).

As ações realizadas foram para coletar dados que permitissem identificar e caracterizar práticas avaliativas inovadoras, efetivadas em sala de aula. Neste caso, o uso do portfólio como ferramenta para monitoramento do processo de ensino e aprendizagem. Não se pretendeu apenas descrever os fatos, mas entendê-los a partir dos conceitos teóricos estudados, num vaivém entre reflexão, observação e interpretação, à medida que a análise progrediu (Laville, 1999, p.228).

Foram objeto de análise os portfólios produzidos pelos alunos durante o desenvolvimento do projeto, constituindo-se em ricos 
documentos, especialmente pelas reflexões neles contidas. As tarefas propostas para o acompanhamento e as reflexões elaboradas pelos alunos foram importantes fontes de dados, pois continham informações sobre as atividades didáticas propostas aos grupos e a descrição da sua realização na dinâmica dos acontecimentos em sala de aula. Esses materiais foram o foco principal das análises, permitindo entender os significados, as condutas dos alunos e os acontecimentos.

\section{O PORTFÓLIO EM AÇÃO}

Não se trata, nesta parte do trabalho, de elencar atividades em uma seqüência de ensino e aprendizagem, nem oferecer modelos para serem seguidos no cotidiano. A pretensão é compartilhar um processo, cuja característica é dinâmica e cheia de nuanças, e oferecer as reflexões que o trabalho permitiu. A captura de alguns exemplos citados no trabalho é apenas uma parte dos acontecimentos ocorridos durante o desenvolvimento do projeto. Fundamentar esses exemplos e apresentar como os envolvidos - alunos e professora - definiam e valorizavam a prática emergente de avaliação formativa foi uma experiência marcada por complexidades.

Nos planos de curso formulados, durante os cinco anos, estavam estruturados os conteúdos, declarados os objetivos e competências pretendidas, bem como padrões e critérios de avaliação a serem utilizados. Tal documento foi colocado à disposição dos alunos e distribuído individualmente no primeiro dia de aula.

Em cada plano, os objetivos foram agrupados por temas a serem tratados e considerados como ponto fulcral para o monitoramento das aprendizagens. Tais objetivos exigiam que os alunos, ao final do curso, fossem capazes de demonstrar conhecimento, compreensão e aplicação de conteúdos fatuais e conceituais, procedimentais e atitudinais (Zabala, 1998; Coll, 2000). Os conteúdos conceituais diziam respeito: às teorias contemporâneas sobre as competências necessárias ao professor; aos conceitos de Didática e sua implicação na formação do professor; ao planejamento, etapas e elaboração.

Os conteúdos procedimentais referiam-se ao "fazer", à realização de variadas ações ordenadas, tantas vezes quantas fossem necessárias, para a concretização de objetivos de ordem prática, sempre aliados a um processo reflexivo a respeito da atividade desenvolvida.

Os conteúdos atitudinais diziam respeito especialmente a: aprender a fomentar a própria aprendizagem; aprender a mobilizar os 
conhecimentos para enfrentar novos problemas e criar soluções alternativas; aprender a extrair fatos pertinentes de fontes diversas; aprender as relações funcionais entre os saberes escolares e a vida.

Os objetivos referentes aos conteúdos explicitados foram refinados durante o processo e representavam o mais importante a ser desenvolvido na disciplina naquele contexto. Isto porque o processo de ensino e aprendizagem é dinâmico e passível de alterações sempre que as circunstâncias assim o exigirem. Perrenoud (1999, p.111) assiná-la que será preciso retificar o alvo constantemente. Corrobora este pressuposto Estrela (1994), ao afirmar que a reformulação constante dos meios para se chegar aos objetivos constitui a principal preocupação ao longo do processo didático.

Os procedimentos usados durante o processo de interação didática foram centrados em aulas expositivas, discussões, seminários, trabalhos de construção de texto coletivo, trabalhos individuais, entre outros. As aulas, compreendidas na dinâmica das relações entre seus atores, privilegiando metodologias ativas, tiveram como característica a diversidade e a flexibilidade, sempre com o intuito de colocar os alunos em situação de desafio para aprender, pois, quando se sabe exatamente o que se quer obter com determinadas aprendizagens, pode-se organizar a aula de maneira rigorosa e dinâmica ao mesmo tempo (Meirieu, 1998).

Permitiu-se sempre um espaço de diálogo, compartilhando responsabilidades. Os alunos tinham abertura para pedir informações complementares que os ajudariam a encontrar respostas às situações com as quais eram confrontados. A via de comunicação professor/aluno não tinha o sentido de dar respostas prontas, mas de desenvolver atitudes favoráveis de comprometimento, de convivência, de solidariedade e de incentivo na busca de informações, independentemente do auxílio da professora, mas estimuladas por ela.

Jonnaert (2002) lembra que se o espaço de diálogo e cooperação não é definido, nenhuma interação pode ser estabelecida entre os parceiros: o professor, o aluno e o saber. Por isso, estabelecer de forma positiva o diálogo entre o professor, os seus alunos e o objeto de aprendizagem é indispensável, e o professor tem papel significativo no estabelecimento dessas relações. No entanto, se o aluno não assumir seu papel de aprendiz compromissado com o seu autodesenvolvimento, a proposta não se concretiza, pois, o que mobiliza um aluno, o que o introduz em uma aprendizagem, o que the permite assumir dificuldades da mesma [...] é o desejo de saber e a vontade de conhecer (Meirieu, 1998, p. 86).

Para cada tarefa trabalhada, foi solicitada uma reflexão, que evidenciasse os ganhos de aprendizagem após o estudo dos conteúdos. 
Previa-se que os estudantes fossem capazes de demonstrar e justificar que tipo de desenvolvimento a tarefa possibilitou.

Partiu-se do pressuposto de que ao serem levados a refletir sobre o que fizeram, acerca do esforço que empreenderam e a respeito do resultado a que chegaram, os alunos poderiam perceber que o processo de formação não se dá de forma acrítica e rotineira, limitado apenas a "fazer" a tarefa. Capacidades de pensar, elaborar, sintetizar, formar opinião, argumentar precisam ser exercitadas. Sem elas não é possível reconstruir os conhecimentos. Portanto, a reflexão é um modo de fazer reviver e de fazer a recaptura da experiência com o objetivo de a inscrever num sentido, de aprender a partir dela e de, nesse processo, desenvolver novas compreensões e apreciações (SáChaves, 1998, p. 138).

A reflexão também teve por objetivo colocar os envolvidos numa situação de assumir a própria aprendizagem, cobrando de si mesmos a responsabilidade em construir seus conhecimentos, além de avaliar seu grau de envolvimento nas atividades, situando-o no seu próprio aprendizado (no que adquiriu ou não).

É bom lembrar que nem por isso a tarefa da professora tornou-se mais simples. Ao contrário, continuou complexa e difícil. Além de lidar com a resistência natural da novidade, empenhou-se em trabalhar com as situações de aprendizagem. Como retrata Jonnaert (2002, p. 249) tratar o saber para colocá-lo em situações tais que existam interações entre esse saber e os conhecimentos dos alunos, bem como colocar seus alunos em condições tais que se estabeleçam interações sociais entre alunos e alunos, e entre alunos e ele, foi uma tarefa árdua. Organizar o espaço e o tempo, controlar e articular o que se passava na sala, agir de forma decisiva sobre acontecimentos inesperados, foram atributos necessários para tal empreendimento. E foi sempre com a intenção de ensinar e de que os alunos aprendessem que a professora propôs as atividades e solicitou as tarefas.

Para as diversificadas situações didáticas, procediam-se avaliações contínuas, procurando verificar a convergência para os objetivos pretendidos. Quando da entrega das atividades solicitadas, a professora analisava seu conteúdo e forma, dava feedback e orientava. Os alunos tinham oportunidade para refazê-las, quando necessário.

Após cada tarefa, foi solicitada uma reflexão livre e pessoal sobre os ganhos de aprendizagem nas áreas trabalhadas: saber, saber fazer e saber ser. Esse exercício reflexivo objetivou auxiliar na tomada de consciência e no desenvolvimento da competência relacionada à auto-reflexão, tão importante quanto demonstrar os progressos feitos.

Um roteiro não estruturado foi distribuído, deixando para os alunos elaborarem livremente seus portfólios a partir das tarefas 
solicitadas. Levou-se em conta que eles mudam progressivamente sua relação com o saber (Hadji, 2001) e que, ao retomar as atividades, podem se dar conta de elementos e relações que antes não tinham percebido. Eram livres para refazer e/ou adaptar a tarefa inicial em razão das novas aquisições, lançando um olhar mais atento sobre elas e sobre suas próprias evoluções. Esta foi uma forma de ensinar os alunos a fazerem uma retomada critica desses deveres [de forma] que lhes permitisse melhorar seus desempenhos (Meirieu, 1998, p.108), numa decisão, às vezes espontânea, de avaliar o trabalho realizado.

Por várias vezes, percebeu-se que os alunos careciam de mais indicações, além das planejadas e operacionalizadas. Em alguns grupos o processo, por não ser familiar, intimidava. De fato, diante do desconhecido, de um problema a resolver ou de um desafio, os alunos são mobilizados a buscar soluções cujos mecanismos ainda não dominam. Isso, a princípio, leva-os a demonstrar insegurança e até manifestar a sensação de impotência para dar conta da tarefa. É o que mostram algumas reflexões contidas no portfólio: fiquei angustiada, senti falta de mais explicações com exemplos [...]. Por ser um trabalho novo, não conhecido, criou ansiedade, desequilíbrio e medo em mim, e acho que no grupo (A10). Uma dúvida se conseguiria ou não realizar o trabalho apareceu, e achei que seria difícil fazê-lo (A5). O desafio e a sobrecarga que senti me fez pensar que não daria conta de maneira satisfatória (A3).

Ao propor as atividades, a professora intencionou torná-las acessíveis, mas suficientemente desafiadoras para mover os alunos em busca de solução. Mesmo que inicialmente difíceis do prisma dos alunos, eram adequadas aos objetivos e ao nível de desenvolvimento pretendido. Eles nem sempre tinham consciência de que o problema ou o obstáculo, colocado voluntariamente, era necessário e até indispensável para a construção de seus próprios conhecimentos (Jonnaert, 2002).

\subsection{O Portfólio: responsabilidade partilhada}

O portfólio, sendo uma coletânea ou um conjunto de excertos seletos de diversos trabalhos, exigiu cuidadoso planejamento para determinar tudo o que a pasta deveria conter para que refletisse ou evidenciasse as competências e/ou habilidades previstas no início do curso. Exigiu também determinação dos documentos evidenciadores das aprendizagens ocorridas durante o período da oferta da disciplina. Tais documentos originaram-se de atividades como: entrevistas, seminários, registros, diários, análise de protocolo de observação, trabalho cooperativo, 
simulações, trabalhos escritos, dramatizações - todos relacionados aos conteúdos e competências previstos.

Os documentos analisados e que compunham os portfólios eram trabalhos com ou sem notas, trabalhos em andamento, descrição de realizações, artigos, resumos, análises, reflexões e auto-avaliações.

Houve uma diversidade de proposições para apresentação dos trabalhos nos vários grupos que participaram do projeto. Para alguns, logo no início, foi definido que seria permitido inserir trabalhos desde o seu esboço, anotações, rascunhos e cópias finais como ilustração do que cada aluno fez para chegar ao produto, como ocorreram as aprendizagens e como abordaram os problemas. Para outros, foi estipulado a apresentação apenas do produto final de cada unidade, com uma reflexão esclarecedora da trajetória e postura pós-aprendizagem.

A definição de como seriam arquivados ou guardados os documentos ou amostras, coube a cada aluno. Apenas solicitou-se a todos os grupos que os containers fossem fortes para suportar manuseio e de tamanho suficiente para conter diferentes mídias. Também que fossem passíveis de ser fechados, fáceis de guardar, se possível personalizados. Isto levou ao uso de pastas tipo arquivo, sacolas decoradas, caixas de presente, caixa de pizza, caixa de sapato, pasta com página bolso, entre outras.

Foi importante definir itens que necessariamente deveriam ser incluídos no portfólio, como manifestação de domínio das habilidades e competências pré-definidas, para facilitar as fases de coleta e desobstrução (Crockett, 1998). Tal lista permaneceu aberta a acréscimos, considerando que alguma tarefa não planejada poderia ser introduzida sempre que necessário, para a consecução de alguma competência ou habilidade. A gerência foi do aluno, embora alguns conteúdos tenham sido determinados pela professora.

A experiência dos cinco anos demonstrou que embora o aluno tenha condições de tomar decisões sobre o que melhor representa suas competências, em geral, sente-se inseguro quanto a que amostras escolher. Por isso, guardar todo material adicional foi do arbítrio de cada um, em todas as turmas submetidas à proposta. Esta sugestão deu um pouco mais de segurança, já que eles poderiam sempre recorrer ao material adicional para demonstrar alguma aprendizagem.

Foi reservado um espaço de tempo (mais ou menos a cada dois meses) para que os alunos recuperassem seus portfólios, verificassem seu conteúdo, incluíssem o necessário e tomassem decisões sobre a manutenção dos trabalhos e o que precisava ainda ser coletado. 
No tocante à avaliação, tal como sugerido por Crockett (1998), critérios para escolha dos trabalhos que deveriam permanecer no portfólio foram propostos por meio de indicações diferentes nas turmas que passaram pelo processo, por exemplo:

Apresente todas as tarefas solicitadas.

Das atividades realizadas, guarde as que considera mais relevantes.

Mantenha três das tarefas realizadas, sem se preocupar com a nota que recebeu.

Arquive as atividades que foram compartilhadas e selecionadas junto com seus colegas.

Em algumas turmas, a opção foi por uma combinação dessas instruções, já que em todas elas o aluno tem "um certo poder", aprendendo a fazer escolhas conscientes.

Na terceira turma, foi adicionada, a título de experiência, a análise dos conteúdos dos portfólios por equipes formadas na sala de aula. Os colegas, em geral, são críticos rigorosos quanto ao que deve permanecer, ao que deve ser retirado ou reeditado. Neste caso, os alunos foram até mais rigorosos do que seria a professora. Impediram alguns de entregar o portfólio incompleto ou com restrições de evidências que permitissem perceber o alcance do que se propusera como meta.

Esse trabalho também favoreceu o engajamento dos alunos no processo de compartilhar seus portfólios, ganhando destaque a prática de explicar e defender a inclusão de determinados documentos, como salientam aqueles que têm trabalhado com a ferramenta.

Por serem os portfólios uma espécie de "memória" de um conjunto de eventos, cada documento tem um significado e representa alguma coisa importante. Preservar este momento, fato, impressão, atitude ou intenção foi também um dos objetivos do portfólio, conforme apregoam seus defensores.

Mesmo sendo um documento individual, particular, os alunos foram orientados para terem alguns cuidados que os auxiliassem na conservação das amostras contidas nas suas pastas e facilitassem a localização e análise. Cada item/documento inserido no portfólio foi identificado por etiqueta ou carimbo contendo: nome, data, título ou legenda descritiva, natureza da amostra; enfim, elementos importantes para o manuseio.

Para aqueles que quisessem inserir fotos e desenhos, foi solicitado que explicitassem quem os fez, quem ou o que era, quando foram feitos, por que foram feito. Essa identificação deveria seguir as normas definidas pela Associação Brasileira de Normas Técnicas (ABNT). 
Os portfólios foram apresentados encadernados, visualmente agradáveis, ordenados, indicando de forma sintética os ganhos de aprendizagem, focalizando o processo e o produto obtido.

$O$ formato sugerido para a apresentação foi o seguinte: capa ou folha de rosto com os dados gerais do aluno; sumário que indicasse a organização do portfólio; prefácio ou apresentação do conteúdo da pasta; amostras dos trabalhos realizados na seqüência, julgados mais interessantes, seguidos de uma reflexão ou comentários sobre o processo para obtenção do produto; amostras opcionais explicando o porquê de sua inclusão.

Foram solicitadas atividades reflexivas, presumivelmente motivadoras e capazes de estimular o aluno ao autoconhecimento. Assim, uma das atividades iniciais foi a construção do próprio perfil, por meio de uma autobiografia.

Nesta tarefa, a criatividade foi bastante estimulada, assim como em todo o desenvolvimento do trabalho. Todos os demais documentos, já tendo sofrido uma triagem, representando o que de melhor foi produzido, bem como as maiores conquistas acadêmicas e pessoais, completaram o portfólio.

Outra amostra foi o prefácio, cujo objetivo foi verificar a habilidade de organizar o pensamento, resumir informações acerca da composição do portfólio e explicar por que e como o desenvolveu.

Amostras escritas como artigo, resenha ou texto produzido pelo próprio aluno, tiveram por objetivo evidenciar o domínio do conteúdo e seu processo de comunicação.

Também foram solicitadas cartas-convite que apresentassem o conteúdo desenvolvido, objetivando demonstrar a capacidade de interpretar informações e editá-las.

Amostras produtivas foram as apresentações escritas de contos, poesias, letras de música, peças de teatro, livro infantil, no sentido de evidenciar o resultado da aprendizagem de conteúdos e também a habilidade de extrapolação, interpretação e uso das diferentes linguagens.

Itens como anotações, trabalhos artísticos, registros de leitura, registros de viagens de cunho científico, de visitas para estudo do meio também foram importantes, embora opcionais.

Declarações sobre si mesmos e registros de performance, habilidades e reflexões sobre o sentimento e ações após cada tarefa foram essenciais para a auto-avaliação e ofereceram condições de perceber quanto a tarefa foi desafiadora, interessante, motivadora ou estressante, difícil, sem sentido. 
Os portfólios foram monitorados em momentos específicos. Pelo aluno quando fez sua auto-avaliação, pelos colegas quando o produto foi compartilhado em equipe, pelo professor, formalmente, pelo menos duas vezes no semestre.

Tudo foi foco de análise. Desde o planejamento e a organização até a produção, revisão e/ou manutenção das amostras, a presença de todas as atividades obrigatórias, tarefas complementares, apresentação aos colegas e o uso do feedback para melhorar o desempenho.

Os trabalhos inseridos na pasta-arquivo não foram passíveis de nota, porque o produto portfólio em si, por ser diferente de aluno para aluno, dificulta um único critério para todos. Considerou-se que uma abordagem que recompensasse atitudes e habilidades positivas, e que não desencorajasse a criatividade e a expressão livre durante todo o processo, seria bem-vinda. Dessa forma, o acompanhamento durante o processo foi a opção. A observação e a análise dos documentos, pela professora, teve foco prioritário durante o processo de ensino e aprendizagem e durante a construção do portfólio. Esta avaliação foi formativa e cumpriu a função de acompanhamento e compartilhamento.

\subsection{Os Episódios}

Para analisar os instrumentos utilizados para monitoramento do processo de ensino e aprendizagem, julgou-se conveniente relatar, também, os procedimentos empregados para o tratamento do tema. Isto porque para cada instrumento utilizado havia todo um contexto preparado.

A seqüência de apresentação ficou assim definida: tema, tipologia dos conteúdos, procedimentos, instrumentos de avaliação e análise. Escolheu-se, aleatoriamente, para este trabalho, apenas um episódio como exemplo do que ocorreu durante o processo. A seqüência didática escolhida aleatoriamente para análise referiu-se ao tema "ensino socializado". O tema foi organizado em atividades que, articuladas, serviriam para: capacitar os estudantes a selecionar e organizar adequadamente os conteúdos a serem desenvolvidos com os seus prováveis alunos; relacionar esses conteúdos a um modo de trabalho; favorecer um processo de comunicação eficiente; subsidiar a análise e reflexão. As atividades foram diversificadas e encadeadas, organizadas tanto em trabalho individual como em pequenos grupos. 


\subsection{A Tarefa Proposta: carta-convite}

Tema: importância do trabalho em grupo na formação docente e na prática pedagógica.

\section{Tipologia do conteúdo}

Saber (conceituais): compreensão da importância da ação individual e grupal na formação docente e as implicações que dela decorrem. Estabelecer elos de ligação entre o significado do trabalho em grupo e os requisitos pessoais (desejáveis) para tal.

Saber fazer (procedimentais): construir a carta-convite, numa linguagem clara e num formato adequado, evidenciando uma comunicação eficiente e demonstrando a compreensão dos conceitos básicos e das técnicas de trabalho em grupo.

\section{Instrumento de avaliação: carta-convite}

\section{Descrição dos procedimentos didáticos}

Durante os cinco anos de aplicação da proposta, foi solicitada, a todos os grupos, uma carta que convidasse alguém para participar de uma equipe de trabalho. A carta-convite foi a tarefa requisitada para fechar o tema e nela deveriam sistematizar os requisitos considerados essenciais para um trabalho em grupo eficaz. Nesse momento, outras leituras já haviam sido feitas e outras experiências do trabalho coletivo já haviam acontecido na sala de aula. Assim, esperava-se que fizessem um resgate dessas atividades, extraindo elementos para construir a carta-convite, que fossem capazes de associar e encadear idéias e transferir o que haviam aprendido, transitando entre as experiências adquiridas dentro e fora da sala de aula.

Deveriam explorar, na carta-convite, conceitos básicos sobre trabalhar em grupo, condições emocionais que envolvem tal trabalho, o que levar em conta para "pertencer" a um grupo de trabalho. Ainda mereciam destaques aspectos relacionados a objetivos do grupo, coesão grupal, envolvimento pessoal, junção de conhecimentos e habilidades, entre outros. O importante não era escrever um "tratado" sobre o tema, mas, de forma simples, resumida e concisa, demonstrar alguns indicadores para um trabalho efetivo em grupo.

No sentido de familiarizá-los e reforçar as informações quanto às normas técnicas de apresentação do trabalho, foi solicitada uma 
apresentação formal para a carta, conforme os indicadores: tamanho do papel, espaçamento entre linhas, tamanho das margens, tipo e tamanho da fonte, formato e posição dos elementos do texto (título, autores, desenvolvimento) e limite de palavras.

Ao analisar os trabalhos, a professora fez comentários escritos para confirmar ou reorientar a aprendizagem dos alunos. Partindo do entendimento de que eles precisam saber o que estão construindo e o que atingiram em relação aos objetivos pretendidos, deu informações e pistas para reelaborarem o que ainda era insatisfatório. As indicações e orientações, quando necessário, tinham a intenção de motivá-los e apoiá-los na superação de dificuldades, dando-lhes novas oportunidades para aprender e ajudando na auto-regulação de seus próprios processos de aprendizagem. De acordo com Perrenoud $(1999$, p. 97) a auto-regulação se dá quando o sujeito é capaz de gerir ele próprio, suas estratégias diante das tarefas e dos obstáculos, monitorando suas aprendizagens de maneira eficaz.

\section{Análise}

Esperava-se que tivessem em mente que o trabalho docente não se dá com indivíduos isolados. É um trabalho coletivo, e como tal exige responsabilidades e relação de empatia para o estabelecimento do bemestar geral entre os indivíduos e seus pares (Vieira, 2000). O processo educativo não envolve apenas técnicas, mas deve acompanhar uma busca de soluções para as diversas situações que se apresentam, articulando saberes e competências (Perrenoud, 1999). Por isso, é fundamental dar ao futuro professor maior número de instrumentos possiveis que o ajudem a lidar com situações diversas dentro do contexto escolar, ao mesmo tempo, que aumentem a sua autoconfiança e sua eficácia em termos profissionais (Vieira, 2000, p. 9)

Fazer com que os alunos trouxessem os conhecimentos para o contexto, a fim de dar-lhes novos significados, incitar a busca de novos saberes, comunicar idéias, foram construções possíveis, confirmadas pelo depoimento:

Para chamar alguém para trabalhar em grupo é preciso ter conhecimento dos requisitos que se quer. Exige que se conheça mais para não ficar só achando que é uma coisa e outra. Aprendi que preciso saber dizer quais são esses requisitos, $e$ para isso tive que pesquisar mais. (A6)

Para alguns, o trabalho parece ter sido novidade absoluta. Mostraram-se ansiosos para "descobrirem" modelos que deveriam seguir: falar sobre o trabalho em grupo em uma carta foi muito difícil. Não me lembro de ter visto nenhuma com essa característica (A2). [...] a única coisa que me vinha à 
mente é que não podia ser um anúncio. Mas não tinha a menor idéia de como elaborá-la (A7). A única coisa que espero é que tenha feito corretamente. Não consigo saber se o que estou fazendo é isso mesmo [...] (A8).

Diante do novo desafio/dificuldade, desencadeou-se um movimento de procura de informações e busca de soluções para direcionar o trabalho. Atividades desafiadoras e, às vezes, até desestabilizadoras das representações anteriormente formadas, imprimem nos alunos a necessidade da pesquisa, a fim de captar informações pertinentes. Meirieu (1998) lembra que propor uma situação problema não quer dizer que a aprendizagem e os conhecimentos vêm naturalmente, mas ela põe o sujeito em ação e em condições de dinamizar suas aprendizagens: eu tive que procurar a informação. Pesquisei na biblioteca, perguntei para meus colegas, folheei revistas e observei alguns anúncios, sem muita certeza se ia encontrar alguma coisa (A8). Comecei a observar tipos de cartas diferentes e percebi que não têm um padrão, a não ser as cartas formais. Aí comecei a criar minha própria carta (A3).

Certamente, os alunos sabem que precisam obter resultado com as atividades solicitadas. Percebeu-se, porém, que nem sempre têm predisposição para aprender, pensar e agir consistentemente e de maneira favorável em relação ao que foi requerido. Envolvem-se de maneira diferenciada, manifestando, às vezes, uma atitude negativa e resistente diante da tarefa, interpretando-a apenas como sendo uma exigência da professora, conforme relata a aluna: esta atividade não teve nenhum significado nem utilidade. [...] além disso ainda tive que refazer a tarefa depois que a professora devolveu (A7).

O comentário da aluna mostra uma visão utilitarista do saber (Perrenoud, 1999), ou seja, ela despende esforço necessário para desempenhar uma tarefa apenas pelas conseqüências (nota, aceitação). Isso faz com que, para a aluna, a atividade tenha um valor apenas instrumental, empobrecendo os procedimentos intelectuais, a curiosidade, a criatividade e a originalidade.

Quanto à crítica sobre trabalho, também pode ser entendida como a oportunidade para a aluna se expressar. Oportunidade esta que pode se constituir em momento de reflexão e crescimento - elementos desencadeadores das transformações necessárias. Nesse caso, a crítica pode ser entendida como uma forma positiva e construtiva. É o que mostra o comentário da mesma aluna:

A carta-convite serviu de base para reflexão para os próximos trabalho em grupos [...]. Preciso apresentar os requisitos, melhorar minhas relações, colaborar com o grupo, etc. O conhecimento que obtive me levou a perceber que preciso destas qualificações para ser boa profissional. (A7) 
O juízo de valor expresso pela aluna mostra, a princípio, um conhecimento ingênuo, sem compreensão e articulação adequada para ligar o conteúdo à estratégia capaz de melhorar a sua aprendizagem. Porém, à medida que conseguiu superar a dificuldade e dar conta da tarefa, foi capaz de compreender o que estava fazendo, refletindo inclusive sobre suas perspectivas pessoais, o que permite concluir que a atividade não perdeu o caráter educativo. Os ajustamentos exigidos serviram não apenas para o progresso acadêmico, mas também para melhorar a capacidade de dominar problemas diante dos novos desafios.

Além disso, a atividade favoreceu o desenvolvimento da autoconfiança e da auto-estima, como relata outra aluna: eu estava bastante insegura ao realizar a tarefa, mas quando recebi a carta de volta e vi que tinha alcançado o objetivo, me senti muito animada e assim como venci o primeiro desafio, com meu esforço, acho que posso vencer os demais (A4).

Articular atividades de modo a conseguir que os alunos encontrem o equilíbrio entre elas, que as incorporem ao seu pensamento e que se valham delas para a resolução de problemas é o desafio para uma ação educativa eficaz e uma exigência da avaliação formativa. Os alunos, certamente, durante toda a sua caminhada, terão que consultar livros, manuais, dicionários, etc, e refletir a respeito de tudo que encontrarem, para que possam realmente desenvolver seus conhecimentos, suas habilidades e suas competências. Haverá sempre, portanto, na vida e na escola, tentativas e erros, recuos e avanços.

\section{CONCLUSÕES}

Este trabalho procurou caracterizar o uso do portfólio como ferramenta de avaliação formativa, identificar e analisar os instrumentos utilizados para avaliação durante o processo de ensino e aprendizagem e analisar a percepção dos alunos sobre seus desempenhos.

$\mathrm{O}$ que ficou evidenciado é que a avaliação formativa permitiu ao próprio aluno "olhar" aquilo que fez, de forma que tomasse consciência do processo e do resultado e melhorasse a eficácia de sua ação. Desenvolver a capacidade de auto-avaliar os conhecimentos e esforços, ajustando-os, quando necessário, a situações novas e à resolução de problemas foi a possibilidade que se abriu. A auto-avaliação capacita o estudante a monitorar a própria aprendizagem.

A auto-avaliação é certamente uma atividade extremamente formadora, quando feita com responsabilidade pelos envolvidos no processo. Confere um status diferente ao aluno pois é ele quem manipula os 
saberes, identificando o que ganhou em aprendizagem e o que ainda precisa interiorizar.

Cardinet (1988, p. 187) afirma que

a progressão no sentido da auto-avaliação confunde-se, efetivamente, com a progressão no sentido da mestria porque o aluno pode alcançar os resultados desejados se for capaz de analisar, ele próprio, as possíveis críticas do seu trabalho inicial e se encontrar meio de corrigir os pontos fracos. Em vez de interiorização, mais ou menos inconsciente, à apreciação global que o professor faz de suas capacidades, o aluno torna-se capaz de um juízo crítico e diversificado de si mesmo, e por repercussão também do professor.

O arquivamento e a análise da documentação permitiram ao aluno refletir sobre a sua produção, perceber a própria aprendizagem em vez de limitar-se a receber a informação; que ele não pode ficar na dependência de que o professor dê respostas certas e afaste as dificuldades. Embora ainda seja dependente da avaliação do professor, a reflexão coloca em lados opostos a atividade de autodeterminação de sua aprendizagem e a passividade de simples execução de instruções (Abrecht, 1994, p. 128).

A avaliação formativa, por ser efetuada no decorrer da aprendizagem, especialmente quando documentada e quando se reflete sobre ela, tem força para auxiliar no processo de aquisição e apropriação dos mecanismos desencadeados pela tarefa e pelas propriedades do tema em estudo. Propor a auto-avaliação é mais do que uma técnica secundária de avaliação, é o meio essencial de transformar o conhecimento do aluno em algo mais que simples competência sobre a qual não refletiu. Levar o estudante a se envolver conscientemente no processo de modo que experimente sucessos, configura o ato amoroso da avaliação (Luckesi, 1996).

O portfólio, até onde foi possível perceber, utilizado como ferramenta de avaliação formativa, possibilitou ao aluno se orientar no processo de aprendizagem, percebendo os caminhos a trilhar e quais obstáculos precisavam ser vencidos. Além disso, o monitoramento do processo, num contexto menos pontual, é uma estimulante forma de fazer ajustes proveitosos no sistema. Segundo Sacristán (1998, p. 309)

as informações mais decisivas que [o professor] utiliza para corrigir os processos de ensino e o trabalho dos alunos não procedem, em geral, de avaliações expressamente realizadas, mas de observações e apreciações obtidas de forma natural no transcurso da interação em aula.

Petitjean (1984, p.14) lembra que é necessária a recolha de informação que leve os professores a articular a prática pessoal, fazendo da própria avaliação 
um objeto de observação e de análise do seu plano de ensino. A avaliação formativa possibilita antever a aprendizagem: fornece elementos que orientarão as aprendizagens posteriores, dando pontos de referência, rumos a seguir, saídas possiveis (Abrecht, 1994, p. 126). Ao trabalharem para promover a independência do aluno, [os professores] estão realmente os ensinando a serem responsáveis pelo próprio aprendizado e dando-lhe as ferramentas para assumirem isso com equilíbrio e com segurança (Hargreaves, 2001, p. 193).

A proposta do uso do portfólio como ferramenta de avaliação formativa mostrou-se coerente com o entendimento de uma avaliação colocada a serviço da aprendizagem, conectada no processo e não apenas como um momento estanque.

O portfólio incorporou diferentes instrumentos que permitiram variadas informações sobre as aquisições possíveis e ajustes necessários. Isso o fez rico e promissor. A variedade na construção e apresentação, a análise e reflexão do que foi mais relevante durante o percurso, incitaram o envolvimento dos alunos no processo de ensino e aprendizagem. $\mathrm{O}$ aluno teve a percepção de que não é um agente passivo, mas que é solicitado a avançar na construção e reelaboração de seus conhecimentos. O portfólio pode ser entendido como um facilitador para este empreendimento.

[...] Sei que aprendi muito ao ler os textos, ao fazer as atividades. Mas sei que não pára aqui. Tenho que buscar incessantemente formas de atuar melhor e ser capaz de dar justificativas consistentes sobre minha atuação, sobre as escolhas das estratégias para colaborar no aprendizado dos meus alunos. (A9)

Para a professora foi de extrema valia, pois, através dele, foi possível obter informações sobre os progressos e as dificuldades dos alunos, sentimentos vividos durante o processo e receber feedback sobre a sua atuação. Com base nessas informações, organizar o ensino, tendo por objetivo promover a continuidade das aprendizagens, foi tarefa menos complexa e mais segura.

Para ambos, o uso do portfólio apontou possibilidades de novas formas de promoção da aprendizagem e de melhoria das relações estabelecidas na sala de aula, uma vez que permitiu detectar os pontos fortes e extrair informações daquilo que ainda precisa ser substanciado, e sobre o que enfatizar. Mas nem tudo são "flores". É trabalhoso, exige tempo e nem sempre é tão confiável quanto ao conteúdo adquirido e a exposição de sentimentos quanto ao processo.

Em alguns casos, há ambigüidades quando comparadas as reflexões contidas nos portfólios com a percepção da professora, o que torna difícil apreender os níveis de compreensão obtidos. A falta de comunicação aberta impõe limites para uma intervenção apropriada e impede a localização de 
dificuldades que ainda permanecem. Isso não favorece a regulação intencional, cuja intenção é determinar ao mesmo tempo o caminho percorrido por cada um e aquele que resta a percorrer, com vistas a intervir para otimizar os processos de aprendizagem em curso (Perrenoud, 1999, p. 89).

Às vezes, os alunos omitem aquilo que não sabem, por isso a necessidade de um trabalho com portfólios que comportem variados instrumentos de avaliação, levando o aluno ao estudo de diversos temas, ao estabelecimento de relações, ao aprofundamento do assunto, inclusive provas tradicionais, embora isto cause um "motim" na sala de aula, por falta de compreensão dos seus objetivos. Felizmente, foram reações raras no período de investigação.

Há, certamente, necessidade premente de desenvolver nos alunos princípios éticos de integridade, honestidade, responsabilidade pelo que é apresentado como resultado e ganhos de aprendizagem, esforço e apropriação dos conhecimentos. Sem esses princípios não há como desenvolver um trabalho complementar. Este é o risco do uso do portfólio como ferramenta de avaliação formativa, mas é também a sua possibilidade, pois ao permitir uma compreensão reflexiva, pode aprofundar o entendimento de que esta é uma parte valiosa da instrução, portanto precisa estar baseada em confiança, reciprocidade, verdade e integridade. Esses valores são construídos ao longo do tempo, quiçá durante toda a vida.

Outra limitação a ser destacada é a resistência dos alunos com relação à diversidade de técnicas de avaliação, nada convencionais: 0 ritmo é muito intenso [...] são muitas coisas para pensar, para fazer. As atividades consomem minhas forças mentais e físicas. Acho que não precisa tanto! (A7).

À medida que a avaliação formativa admite atenção ao processo, à aprendizagem como movimento, [...] já não se submete ao pontual [...], para poder interessar-se totalmente pelo temporal, pelo contínuo, é nessa medida que ela pode provocar resistências (Abrecht, 1994, p.164).

A resistência pode impedir descobertas pessoais. É preciso arriscar, expor fraquezas para, aos poucos, se estabelecer o que é significativo. Segundo Hadji (2001b, p. 87), para aprender é preciso, antes de mais nada, aceitar a situação de aprendizagem, receber o objeto com o qual será confrontado; e completa: isso só é possível na medida em que se é movido por um desejo de mudança, mais forte que o temor do desconhecido.

Outro aspecto a ser considerado é que, mesmo tendo entendido o que era esperado deles, alguns alunos apresentaram, no portfólio, pouca ou nenhuma reflexão, e alguns itens que pouco comprovaram o aprendizado. Considerando que esses alunos são professores em formação, é imprescindível que eles mesmos se submetam à análise crítica do seu 
desenvolvimento e daquilo que apresentam como evidências de aprendizado. É certo que a aquisição de conhecimentos é um processo progressivo, inacabado e diferenciado, porém naquele momento deviam representar o seu "melhor", ainda que fosse necessário um refinamento. É preciso apresentar trabalhos de qualidade e excelência, e importa que após uma avaliação séria, isenta e rigorosa, sejam considerados como tal (Alarcão, 2001, p. 55). Desenvolver no futuro professor o primor pelas suas realizações foi a oportunidade que se apresentou e que a maioria significativa dos alunos aproveitou muito bem.

Outra preocupação é o tempo que os portfólios requerem para sua implementação e gerenciamento. Primeiro, porque não se pode pretender trabalhar com portfólios sem conhecê-los. Obter informações teóricas, bem como seus limites e possibilidades, antes de se aventurar a aplicá-los, é indispensável. Segundo, por evidenciar competências e habilidades pessoais, o feedback, quase sempre, é individual. Terceiro, para que haja entendimento da proposta, os alunos devem ser bem informados sobre como fazer e por que fazer. Nem sempre informações verbais são suficientes. Colocar materiais com instruções adicionais, ter abertura para momentos de tirar dúvidas podem ser necessários, acrescendo o tempo de trabalho do professor. E, por último, os resultados dos portfólios e a interação com os alunos, às vezes, podem apontar para seqüências didáticas diferentes das previstas, para o equilíbrio dos projetos e ações, demandando, com isso, mais tempo para planejar e refletir sobre a eficácia das formas de atuação.

Da parte dos alunos, o tempo também é referido, visto que precisam planejar, coletar, organizar e completar seus trabalhos: a falta de tempo não deixa muito espaço para fazer as coisas como deveria e refletir de forma adequada sobre tudo que tenho aprendido. Tudo fica atropelado (A9).

Às vezes, pressionados pelas exigências de um currículo extenso e horários reduzidos, acabam tendo pouco tempo para refletir e compreender os conceitos fundamentais, para expandir os seus quadros de referência e para desenvolver uma aprendizagem significativa, e passam superficialmente pelas atividades, comprometendo a qualidade de suas aprendizagens (Chambers, apud Alarcão, 2001, p. 112). Além disso, os portfólios demandam grande responsabilidade em termos de autoadministração, auto-avaliação e auto-reflexão (Melograno, 1996).

Apesar das contra-indicações e cuidados necessários, o portfólio permitiu que o trabalho e as realizações fossem vistas pelos próprios alunos sob diversas perspectivas e que a complexidade de suas habilidades e identidades fossem reconhecidas. Tiveram mais voz e visibilidade para suas atividades e realizações diversas através dos meios de comunicação escritos, orais, 
visuais, tecnológicos ou dramáticos, os quais incorporam uma mistura de estilos (Hargreaves, 2002, p.63). Eles mesmos fazem referência a essa forma de avaliação como possibilidade de descobertas inesperadas, interessantes e promissoras, justificando espontaneamente o trabalho, inclusive em momentos informais.

Os materiais relacionados aos objetivos pretendidos, as atividades que após a avaliação da professora tiveram de ser refeitas e as reflexões foram de absoluta importância para evidenciar o progresso dos alunos em termos do saber, saber fazer e saber ser. Também se percebeu quanto evoluíram ao planejar, coletar, organizar e completar e/ou refazer suas apresentações no portfólio.

Tendo em vista os depoimentos constantes nos portfólios e na entrevista, é possível afirmar que todos fizeram consideráveis avanços, mesmo os mais resistentes. Buscaram informações, sintetizaram, alinhavaram textos e informações, produziram, fizeram auto-avaliações e ao escreverem suas reflexões substanciaram seus avanços. Na maior parte das vezes, houve congruência entre as realizações e os objetivos.

Os alunos tiveram momentos para se auto-avaliarem. Em certo sentido, eram "donos" de suas ações ao tomarem decisões sobre a documentação da pasta. Desencadearam processos de investigação, não esperando passivamente por modelos, soluções e respostas somente da professora. Esta busca foi salutar para a autonomia dos alunos.

Percebeu-se, também, o esforço e a criatividade para apresentação das produções acadêmicas. O estímulo à capacidade criativa teve um efeito motivador para que os alunos procurassem a melhor forma de comunicar os resultados das suas atividades. Este é mais um aspecto favorável do uso do portfólio. Embora algumas atividades devam seguir rigorosamente as normas de apresentação de trabalho acadêmico, outras permitem a inovação e favorecem o desenvolvimento de diferentes habilidades, que em outras situações não são privilegiadas.

[...] procurei aliar as atividades do portfólio com arte e conhecimento. Decidi criar meu próprio personagem. Ousei [...]. A princípio tive um pouco de dificuldade e receio, mas conforme ia fazendo as atividades, as idéias iam surgindo [...] Chego ao final com grande satisfação pelo trabalho que fiz. (A11)

Os benefícios do portfólio para a avaliação não são automáticos, e também não dependem dos portfólios em si, mas do que os alunos aprendem ao criá-los e ao alimentá-los (Crockett, 1998; Melograno, 1996). Além dos já mencionados, vale destacar que o cuidado em expressar as idéias de maneira clara, a superação de problemas (técnicos, afetivos, cognitivos), o uso de diferentes estratégias, o julgamento das qualidades e 
fraquezas, a compreensão do processo de auto-avaliação foram ganhos que também se observaram.

Conforme demonstrado neste trabalho, a avaliação formativa e o uso do portfólio como ferramenta de avaliação colocam desafios particulares aos alunos e professores. Certamente, o trabalho com portfólio não é perfeito, nem definitivo, nem único, mas se constitui num olhar positivo sobre a avaliação (Hernandez, 1998). O portfólio é uma ferramenta de avaliação promissora que poderá, sem dúvida, inspirar outras possibilidades, além das evidenciadas aqui, pois a avaliação é um processo que precisa ser constantemente refinado.

\section{REFERÊNCIAS BIBLIOGRÁFICAS}

ABRECHT, R. A Avaliação formativa. Rio Tinto, Portugal: Edições Asa, 1994.

ALARCÃO, I. (org). Escola reflexiva e nova racionalidade. Porto Alegre: Artmed, 2001.

CARDINET, J. La Maîtrise, communication réussie. In: HUBERMANN, M. (éd) Assurer la réussite des apprentissages scolaires? Les propositions de la pédagogie de maîtrise. Neuchâtel. Delachaux \& Niestlé, 1988.

COLL, C. Os Conteúdos na reforma: ensino e aprendizagem de conceitos, procedimentos e atitudes. Porto Alegre: Artes Médicas, 2000.

CROCKETT, T. The Portfolio Jouney: a criative guide to keeping studentmanaged portfólios in the classroom. Teacher Ideas Press. Colorado: Libraries Unlimited, 1998.

ESTRELA, A. Teoria e prática de observação de classes: uma estratégia de formação de professores. Porto, Portugal: Porto Editora, 1994.

HADJI, C. A Avaliação desmistificada. Porto Alegre: Artmed, 2001.

A Formação permanente de professores: uma necessidade da era da profissionalização. Revista Pátio. Porto Alegre, v. 5, n.17, p. 15, maio/jul. 2001a.

Pensar e agir a educação: da inteligência do desenvolvimento ao desenvolvimento da inteligência. Porto Alegre: Artmed, 2001b. 
HARGREAVES, A. Educação para mudança: recriando a escola para adolescentes. Porto Alegre: Artmed, 2001.

Aprendendo a mudar: o ensino para além dos conteúdos e da padronização. Porto Alegre: Artmed, 2002.

HERNANDEZ, F. A Organização do currículo por projetos de trabalho. Porto Alegre: Artes Médicas, 1998.

- Cultura visual, mudança educativa e projeto de trabalho. Porto Alegre: Artes Médicas Sul, 2000.

JONNAERT, P. Criar condições para aprender: o socioconstrutivismo na formação de professores. Porto Alegre: Artmed, 2002.

LAVILLE, C. A Construção do saber: manual de metodologia da pesquisa em ciências humanas. Porto Alegre: Artes Médicas Sul, 1999.

LUCKESI, C. C. Avaliação da aprendizagem escolar. São Paulo: Cortez, 1996.

LUDKE, M.; ANDRÉ, M. E. D. A. Pesquisa em educação: abordagens qualitativas. São Paulo: EPU, 1986.

MEIRIEU, P. Aprender... sim, mas como? Porto Alegre: Artes Médicas, 1998.

MELOGRANO, V. J. Portfolio Assessment: documenting authentic student learning. In: Student portfolios: a collection of articles. Illinois: Iri/Slyligth, 1996.

PETITJEAN, B. Formes et fonctions des différents types d'évaluation. Pratiques (revue) L'évaluation, n.44, Dec. 1984.

PERRENOUD, P. Avaliação: da excelência à regulação das aprendizagens entre duas lógicas. Porto Alegre: Artes Médicas Sul, 1999.

As Competências para ensinar no século XXI. Porto Alegre: Artmed, 2002.

SÁ-CHAVES, I. Porta-fólios - no fluir das concepções, das metodologias e dos instrumentos. In: ALMEIDA, L. S.; TAVARES, J. Conhecer, aprender, avaliar. Porto Alegre, 1998. p. 135-141. 
SACRISTÁN, J. G. Compreender e transformar o ensino. Porto Alegre: Artmed, 1998.

VIEIRA, H. A Comunicação na sala de aula. Lisboa: Presença, 2000.

ZABAlA, A. A Prática educativa: como ensinar. Porto Alegre: Artmed, 1998.

Recebido em: janeiro 2006

Aprovado para publicação em: julho 2006 
